scence, change of air is necessary. Among the wealthy, Barbados is the favourite resort. Those whose circumstances will not afford the expenses necessary for the Barbadian trip, find much benefit by change to either of the coasts of the colony, or better still, the uplands of Essequebo.

A circumstance worthy of note in the effects of change of air, and resembling the "nacht kur" imputed to the German spas, is, that while the patient is away, no amendment may take place in his health, nor till after his return to the colony. This nacht kur is of frequent occurrence.

From the tenour of all the previous remarks, it will be perceived that I considered intermittent fever the basis of all the endemic fevers of the colony.

(Signed)

Danier Buair.

George Town, British Guiana, Sept. 1817.

\section{REMARKS ON THE LOCAL TREATMENT OF ERYSIPELAS.}

By J. THOMSON, Ese., M.R.C.S.E., Aberfeldy, Perthshire.

WHAT is the best local treatment of erysipelas in general? and of the face and head in particular? Some say that cold water is the best application, and adopt the plan, even in some hospitals-not, however, with the best results; it must rather repel the inflammation from the skin to the brain, or other deep-seated or distant parts, than subdue it locally, independent of the shock which the nervous system receives in some constitutions from the application of cold to an inflamed surface. Others maintain that nothing should be applied but flour or starch. Armstrong says, in his lectures, "I have no faith in any local applications in erysipelas, and $I$ have abandoned them all, except the use of a little arrow-root dusted gently over the part." This fruitful cause of phlegmonous mischief, wherever it is applied, particularly in the head, neck, armpits, \&c., is the favourite popular doctrine and practice, and is extensively followed throughout the country. It is generally said, " rose must not be wet," and it is remarkable that so many medical men, so far advanced in the nineteenth century, still chime in with the doctrine, and have recourse to this vulgar, cruel, and unscientific application.

I am just recovering from a severe attack of erysipelas of the face and head, and the constant application of warm water over the inflamed surface, while the constitutional treatment was going on, and continued until the inflammation subsided, afforded much relief; then the occasional application of a warm, watery solution of opium, a drachm to a pint, relieved greatly the deep-seated pains in the cellular substance and bones, and, with the aid of a little simple ointment, desquamation took place speedily, and almost imperceptibly.

I question the propriety of applying astringents, such as acetate of lead, as they constringe the pores of the skin, and thus prevent the exudation of the morbid matter, and produce the same effects, more or less, according to their strength-as Hour, starch, or arrow-root, though not to the same extent, (because of the preventive power of the water holding them in solution, or in the same mechanical manner as the latter; the incrustation of which, first over the inflamed surface, then over the dead cuticle, forms an effectual barrier against any cutaneous transudation, and confines the morbid matter under the skin, thereby causing collections of it, by burrowing and gravitating into depending parts. Of course, counter-irritation with the nitrate of silver is sometimes necessary on some parts, in very bad cases; but the warm water alone is the best application over the whole inflamed surface, and, being absorbed by the skin, assists greatly in diluting the deranged fluids-preventing the formation of purulent accumulations - and dispersing them when they have taken place.

Aberfeldy, Perthshire, October, 1845.

$=$

\section{ON THE}

\section{EMPLOYMENT OF CHLORINATED SODA IN THE} TREATMENT OF BURNS AND CARCINOMA.

BY ISAAC PIDDUCK, M.D., \&c., London.

AMONGS the various means employed in the treatment of burns, there is one remedy which I have found of more value than any of the rest. It is a diluted solution of the chlorinated soda. The proportions I use are, solution of chlorinated soda one part; water, six to ten parts. Linen rag, wetted with this lotion, is laid over the part, and covered with a dry piece, to prevent too rapid evaporation. It affords immediate relief from pain, and the part heals without any other application.

Upon the same principle-viz., that of excluding the atmospheric air, and of correcting the irritating qualities of the discharges, $I$ have used a weaker solution of chlorinated soda in the treatment of carcinoma and fungoid disease. The pain is greatly alleviated by it, the foetor of the discharge is corrected, and the sore assumes a more healthy aspect. The testimony of the surgeon in attendance with me in a case of fingoid disease of the lip, originating in a phyma, is, "that it appears to him more useful than applications usually are in such cases." The solution, in the proportion of three fluid drachms to a pint of tepid water, is used as an irrigation to the sore; a basin being placed under the chin to receive the douche as it runs down. To alleviate the neuralgic pains occasioned by the sore, a plaster composed of compound galbanum plaster, ten parts; opium and camphor, of each one part, spread on soft leather, is laid on the sound skin over the chin and side of the face.

Bloomsbury, Nov, 1848 .

\section{Zatoíetos.}

On Femoral Rupture, its Anatomy, Pathology, and Surgery; with a New Mlode of Operating, applicable to cases of Strangulated Hernice generally. With plates. By John Gay, F.R.C.S., Surgeon to the Royal Free Hospital, \&c., \&c. London: Samuel Highley, 32, Fleet-street. 1848. Quarto, pp. 97.

AMoNGST the numerous books that are constantly issuing from the medicai press, there are some which attract more than ordinary attention, either from the particular interest of the subject they treat of, any novel theory propounded, or practice inculcated therein; or from the manner in which the work is put together. The one under notice is very likely to receive considerable attention, as all the reasons mentioned obtain force. The affection which is investigated is one of the most serious in the catalogue of surgical diseases, and is surrounded with so many difficulties, both in a scientific and in a practical point of view, that the most eminent men have devoted a great deal of their time and talents in the investigation of the subject; have simplified the study and practice of hernia; and we think have left little (connected with its anatomy, at least) for other inquirers to find out. But the same cannot be said with respect to the purely practical part. Although much has been done by excellent surgeons to improve the treatment of hernia, and simplify the operative process, - which is not unfrequently necessary, - the mortality from this affection is very great, even in the hands of the most skilful and careful surgeons. It cannot be denied that death follows the operation for strangulated hernia more frequently than it does any other commonly performed capital operation, and it is for the purpose of diminishing this excessive mortality that some surgeons have of late years suggested new methods of operating. With the same laudable object in view, has Mr. Gay set himself to work, and he has not gone abont it carelessly, but has evidently devoted a great deal of time and trouble in the investigation of his subject, and has recorded the results of his inquiries, and the practical deductions he has arrived at in the present work, which is very well executed in most respects.

About one half of the work is taken up with the consideration of the anatomy and pathology of the parts concerned in femoral hernia; and for the purpose of giving a correct description of them, the author tells us he has examined above seventy subjects. As we before said, the anatomy of hernia has been so well investigated, and is so clearly understood, that little has been left for inquirers in the present day to point out, and it may appear to some, that the minute demonstration of the anatomy of femoral hernia here given was a superfluous and an unnecessary task; but as the author is recommending a new operation, and his views with reference to some points in the anatomy of femoral hernia, are in several re- 